Journal Of Al Azhar University Engineering Sector

Vol. 11, No. 39, April 2016, 495-506

\title{
BEHAVIOR OF PRECAST BEAMS JOINTS IN BRIDGES
}

\author{
Ayman Hussein Khalil, Mohamed Nabil and Karim M. Naguib
}

ABSTRACT

Ain Shams University, Cairo, Egypt

In the last few decades, precast concrete has become strongly recommended for the most types of bridges construction due to time saving, quality control and concrete members consistency. In bridges construction, precast concrete elements are connected together in order to achieve bridge deck integrity and stability; joints between these elements shall be able to transmit all internal forces due to service loads safely. The presented paper introduces an experimental study of the performance of stitching joint between precast beams and determines if this detail could generate a precast deck system that could emulate the monolithic cast-in-place deck systems without any advantages to stitching concrete joint over monolithic one regarding material properties.

In this respect, an experimental program was conducted on six specimens which were tested to failure under a static vertical load. Three specimens of monolithic cast-in-place beam to beam connection and three specimens of precast beams with stitching joints were tested using three different positions of vertical load to simulate flexural tension or diagonal tension shear failures. Results obtained by experimental work indicated that stitching joints have a reduced flexural capacity compared with monolithic joints, while two types of joints have the same shear capacity.

\section{Key Words: Bridges, Precast Concrete, Cast-In-Place, Joints Details, Stitching Joint, Monolithic Joint.}

\section{INTRODUCTION}

The very existence of precast concrete industry and the numerous successful bridge projects achieved using precast concrete is a proof that the technique is practical and feasible. Precast bridge construction presents many advantages over conventional cast-in-place bridge construction. First, major time consuming tasks such as the erection and removal of formwork, placement of steel reinforcement, casting of concrete and curing of concrete need not to be accomplished in the work zone; the elements can be prefabricated off-site or adjacent to site, concurrently with the on-site construction, then brought to the site and quickly erected into place. This can significantly compress construction project timeline and reduce traffic disruption. At construction sites, workers are often exposed to dangerous situations such as working close to traffic, near power lines, or over water. Fabricating the elements off-site, in a safe environment, reduces the amount of time workers are exposed to these potentially dangerous situations. The use of precast elements also increases the overall quality of the product, since plant operations are often standardized to ensure quality control. 
Precast concrete beams are usually procured to construction sites as separate units; and in order to achieve integrity of these elements, cast-in-place joints (stitching) between precast beams are used after beams positioning and erection. Cross beams may need to be temporarily supported during casting and hardening of cast-in-place joint.

As shown in Figure1, there are two types of joints between bridge deck beams that shall be compared in this study; monolithic joint which requires all elements to be casted together in place to develop cross beams reinforcement inside main supporting girder. The other type is stitching joint, in which both cross beams and main girders are supplied to construction site as precast units with separate reinforcement details for each beam; only connection portions are required to be casted in place.

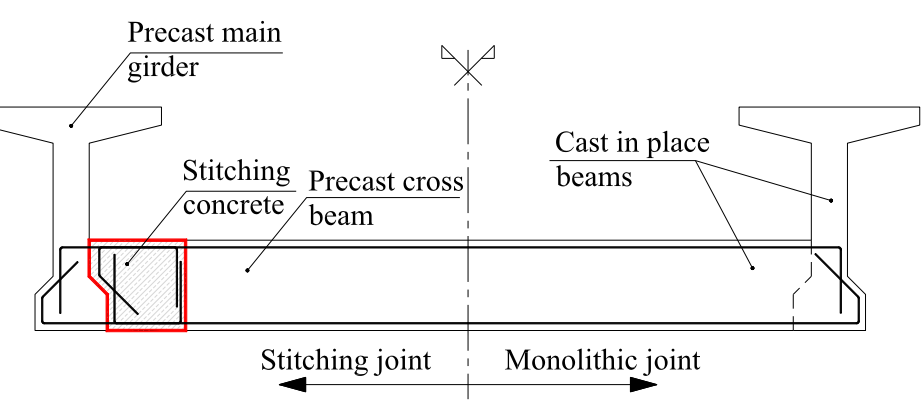

Fig. 1: Monolithic versus stitching joint details between concrete bridge beams

Applications of stitching joints are adopted for other types of precast elements such as parapets and slabs, Figure 2 shows different examples of using stitching joints in bridges construction.

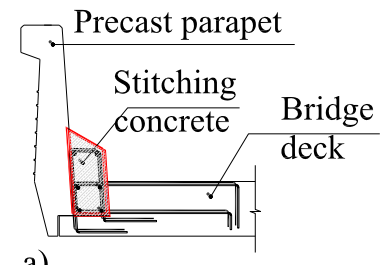

a) b)

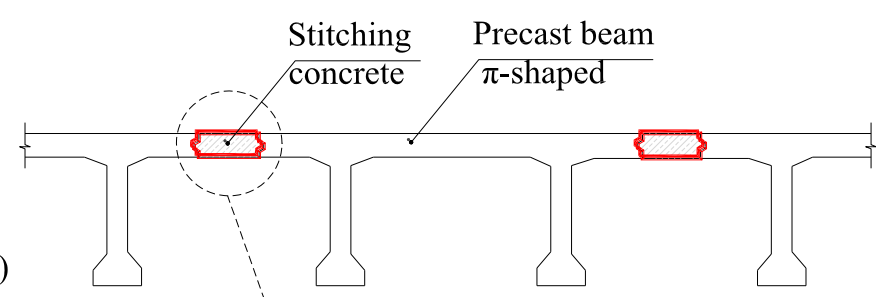

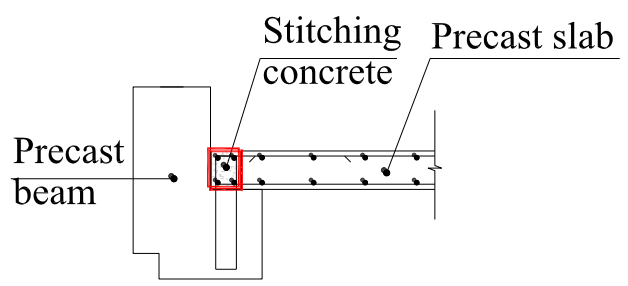

c)

Fig. 2: Applications of stitching joints in bridges; a) connecting precast concrete parapet and bridge deck slab, b) Connecting adjacent precast $\pi$-shaped beams in beam type bridge deck and c) Connecting precast slab with precast beam in pedestrian bridge deck 


\section{LITERATURE REVIEW}

Chapman ${ }^{[1]}$ performed an experimental research on the behavior of the U-Bar joint detail used in precast bridge deck systems. As shown in Figure 3, this detail consists of staggered reinforcement extending beyond the precast deck portion into the joint. The purpose of the testing was to determine if the joint details could generate a precast deck system that could simulate the monolithic cast-in-place deck systems already in use; results have shown that concrete strength has no significant effect on flexural and tensile capacities of joint, while decreasing overlap length and increasing U-bar reinforcement spacing have noticeable reduction in flexural and tension capacities of joint.

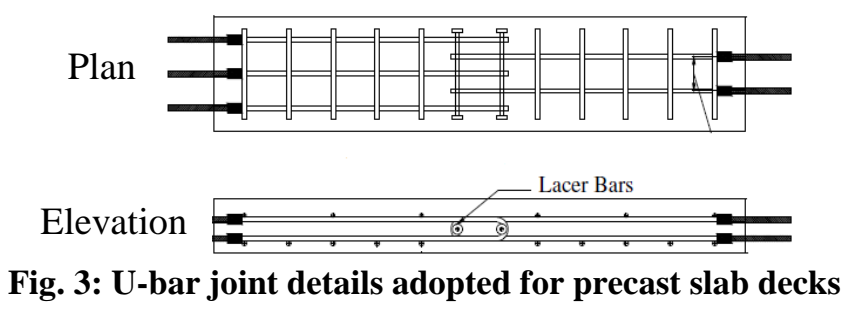

Hajar et al ${ }^{[2]}$ introduced using ultra-high performance concrete (UHPC) for precast joints in bridges in which decks are an assembly of five $\pi$-shaped precast beams made of UHPC. Two flexural tests were carried out on both monolithic and jointed slabs with dimensions matched with those of the flange of the $\pi$-beams. The moment of rupture of the jointed slab was about 416,000 in lbs. (47kN.m), compared to 374,375 in lbs. $(31 \mathrm{kN} . \mathrm{m})$ obtained with the monolithic slab; the bearing capacity of the jointing zones is therefore more than adequate, and their behavior is perfectly satisfactory.

F. Saad ${ }^{[3]}$ has presented the idea of improvement precast slab U-bars joints by the means of GFRP-fabrics, which were glued on the tension side of the casting joint, in order to improve the serviceability limit state in terms of the reduction of the crack width. Different arrangements of the FRP-fabric were tested experimentally under pure bending. It is noticed that an increase in the ultimate strength was observed by about $10 \%$. Regarding service limit state, for a crack width limit of $0.1 \mathrm{~mm}$, the service loads are improved by about $20-50 \%$, while for limit of $0.2 \mathrm{~mm}$, the service loads are improved by $60-95 \%$.

$\mathrm{Li}$, Zhongguo et al ${ }^{[4]}$ focused on an investigation of improved continuous longitudinal joint details for decked precast concrete girder bridge systems. The research presents the results of a study to assess potential alternate joint details based on constructability, followed by testing of selected details. Beam specimens connected with either lapped headed reinforcement or lapped welded wire reinforcement were tested. Based on the survey and the experimental program, a headed bar detail was recommended for replacing welded steel connector detail.

Benjamin A. Graybeal ${ }^{[5]}$ had an experimental study to evaluate the behavior of ultra-high performance concrete (UHPC) connections between precast bridge elements under cyclic loading. The test program included specimens representing connections between two different types of elements; transverse connections being considered for use between full-depth precast deck panels shown in Figure 4-a) as well as longitudinal connections being considered for use between adjacent deck bulb-tee girders as shown in Figure 4-b). Within each of the two sets of specimens, multiple reinforcement configurations as well as lap lengths were tested. There were two phases to the planned structural testing of each specimen; cyclic loading that simulates the fatigue performance of the joint then static loading to failure. Water was ponded on the top of the connection throughout the cyclic tests to evaluate water tightness of joints visually. Both transverse and longitudinal connections details tested are anticipated to perform acceptably in the field. These details were not engaged during the cyclic loading program due to the good interface bonding between the precast and the field-cast UHPC. 

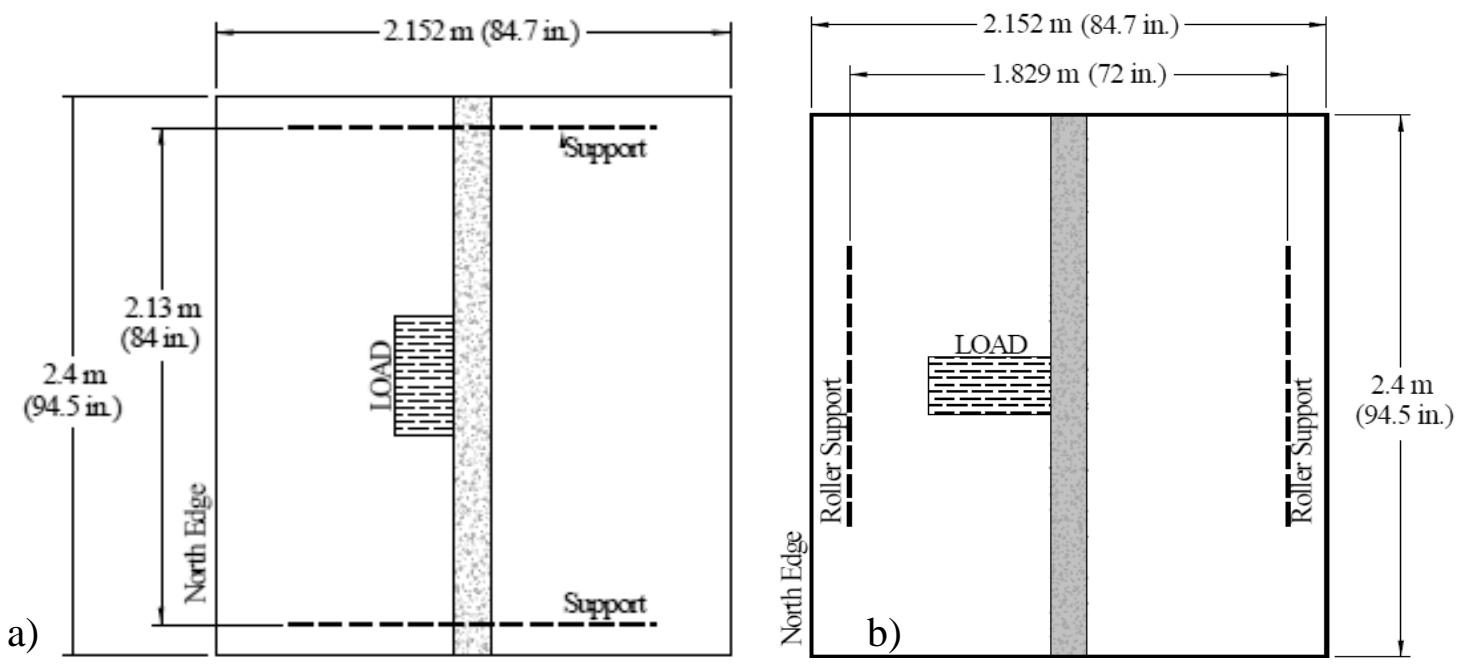

Fig. 4: Test setup sketch for cyclic loading of jointed panels; a) transverse joint considered for full-depth precast panels and b) longitudinal joint considered for adjacent deck bulb-tee girders

\section{EXPERIMENTAL WORK}

\subsection{Experimental Program}

An experimental program was carried out for testing of six beams connections in order to evaluate their structural behaviour and compare among different details to achieve an efficient, stable, and durable joint under different types of actions. The specimens were categorized into two groups; the first group (Group-I) comprised three specimens in which main girders and cross beams were casted monolithically. The second group (Group-II) consists of three specimens; in which each beam was casted separately then the connections were casted later.

The objective of the experimental work is to compare the performance of joint between reinforced concrete beams using different joint details (i.e. monolithic and stitching). The main parameter considered in this experimental study is load position with respect to connection between beams. Three positions were selected to apply a vertical static load and compare joint behavior under different types of actions.

As shown on Figure 5, each specimen consists of main girder with dimensions $300 \mathrm{~mm}$ width $\mathrm{x} 400 \mathrm{~mm}$ depth $\mathrm{x} 2100 \mathrm{~mm}$ length, which supports cantilever cross beam with dimensions $200 \mathrm{~mm}$ width $\mathrm{x} 250 \mathrm{~mm}$ depth $\mathrm{x} 1150 \mathrm{~mm}$ length that is directly subjected to test load. Three positions of loading were selected along cross beam; position (1) was intended to evaluate connection behavior when subjected to flexural tension failure, while position (2) was used to verify connection behavior when subjected to both flexural and diagonal tension shear cracking. Position (3) guarantees shear failure with pure diagonal tension cracking of joint. A summary of specimens details (e.g. joint type and load position) are provided in Table 1.

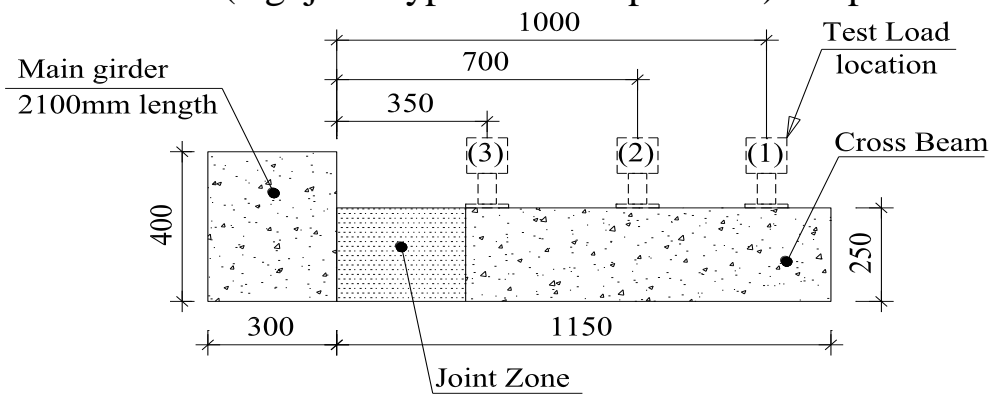

Fig. 5: Specimens typical detail with different load positions used in testing

\subsubsection{Group-I Specimens}


This group of specimens represents cast-in-situ beams, which are casted together with fully developed reinforcement of cross beams inside main girder. This group includes three typical specimens that were tested to failure using the three different positions of test load described in Figure 5. Typical details of reinforcement of group-I specimens are described in Figure 6.

\subsubsection{Group-II Specimens}

This group adopts pre-casting technique in fabrication of beams. In which each beam is casted separately, then transported to site and connected together by the way of cast-in-situ joint which is responsible for transmitting of internal force from cross beams to the main girders, this process was simulated in laboratory by casting beams then casting joint after main girder and cross beam hardening. Interfaces between cast in place and precast concrete were carefully prepared to be clean and rough in order to ensure that there is no failure by shear friction at the surface of interface.

As shown in Figure 7 each beam has its own reinforcement, in other words, reinforcement of cross beam is not developed inside main girder. In this group, three typical specimens were fabricated to be tested by a vertical load from three different positions shown in Figure 5.

Practically, when using precast beams in bridges construction, cast in place parts shall be minimized as much as possible. As such, stitching joint length was limited to $300 \mathrm{~mm}$ (approximately equals to cross beam thickness).

\subsection{Materials Properties}

Concrete mix was designed to produce concrete strength of 40Mpa, which contains the following materials per cubic meter: $400 \mathrm{~kg}$ of cement, $600 \mathrm{~kg}$ of sand, $1200 \mathrm{~kg}$ of dolomite stone, and $190 \mathrm{~kg}$ of water. Eight standard cubes of size $150 \times 150 \times 150 \mathrm{~mm}$ of concrete mixture were fabricated and cured under water, then subjected to axial compression to evaluate the average concrete strength after 7 and 28 days.

Two grades of steel reinforcement were used; first grade was 240/360 plain round bars of $6 \mathrm{~mm}$ diameters, which were used as stirrups for cross beams. The other grade of steel used is 400/600 high strength deformed bars of diameters 10, 12 and $16 \mathrm{~mm}$ that were used as beams longitudinal reinforcement and stirrups for main girders. Standard tension test, using universal tension testing machine, were applied to samples of both mild and high strength steel. Average yield strength measured or both mild and high strength steel bars found to be 242 and 430Mpa respectively.

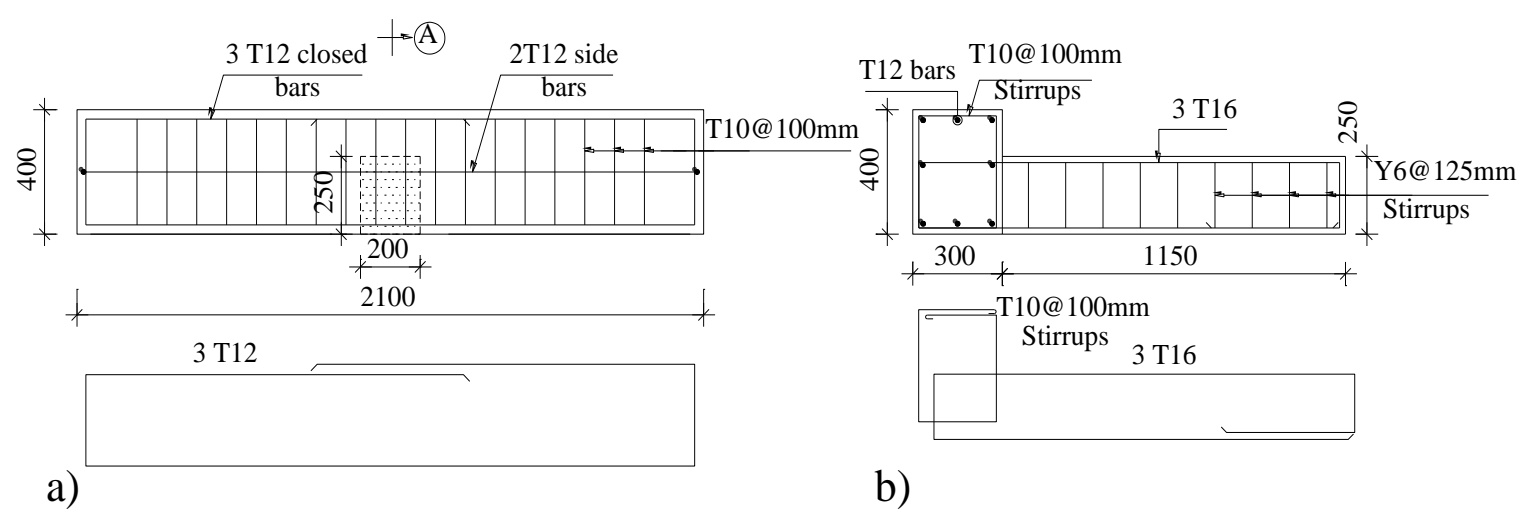

Fig. 6: Group-I "Monolithic joint specimens" reinforcement details

a) Main girder details in elevation, b) cross-section (A) showing cross beam details of reinforcement 


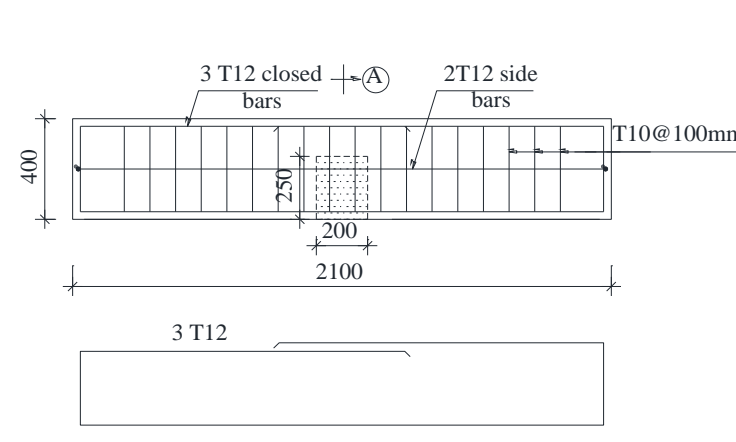

a)

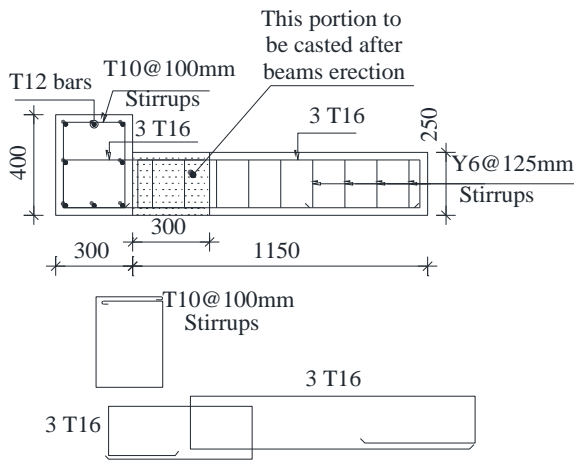

b)

Fig. 7: Group-II "Stitching joint specimens" reinforcement details

a) Main girder details in elevation, b) Cross-section (A) showing cross beam details of reinforcement.

Table 1: Summary of experimental study specimens details

\begin{tabular}{|c|c|c|c|}
\hline Specimen ID & Group & Joint type & Load position $(\mathbf{m m}) *$ \\
\hline S1 & I & Monolithic & 1000 \\
\hline S2 & I & Monolithic & 700 \\
\hline S3 & I & Monolithic & 350 \\
\hline S4 & II & Stitching & 1000 \\
\hline S5 & II & Stitching & 700 \\
\hline S6 & II & Stitching & 350 \\
\hline
\end{tabular}

* Load position is measured from face of main girder; refer to Figure 5 for clarification of load positions.

\subsection{Instrumentation}

Electrical strain gauges with gauge length of $10 \mathrm{~mm}$ were attached to both tension and shear reinforcement of cross beams in order to measure longitudinal strain of steel bars. In addition, strain gauges with gauge length of $60 \mathrm{~mm}$ were fixed to concrete surface at compression side of joint to evaluate compression strain at failure.

Three displacement transducers (LVDT) were used for deformation measurements; two of them are placed under cross beam in order to evaluate performance of these beams under different types of actions and joint details, while the third one was attached to fixation system of main girder in order to ensure that there is no movement due to main girder torsion.

\subsection{Test Setup}

Loading was applied directly to cross beams at three different positions for each group of specimens as shown previously in Figure5. The boundary conditions selected for main girders were fixation against all translations and rotations using assembly of steel plates anchored to loading frame and main concrete beam as shown in Figure 8. Steel supports were designed to prevent all possible movements of main girder.

Steel plates assembly welded together for fixation of main beam against translation and rotation through a group of bolts.
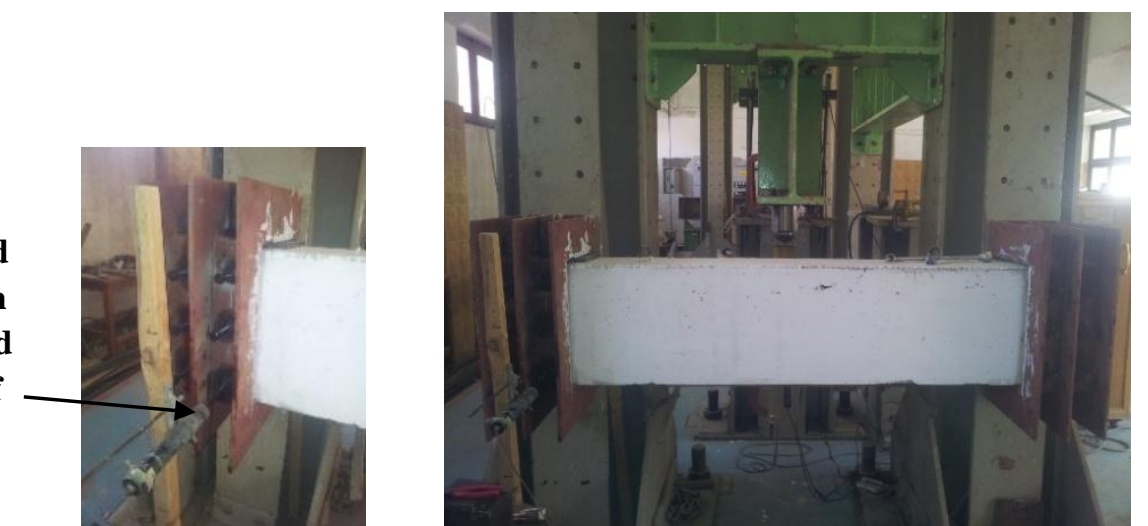

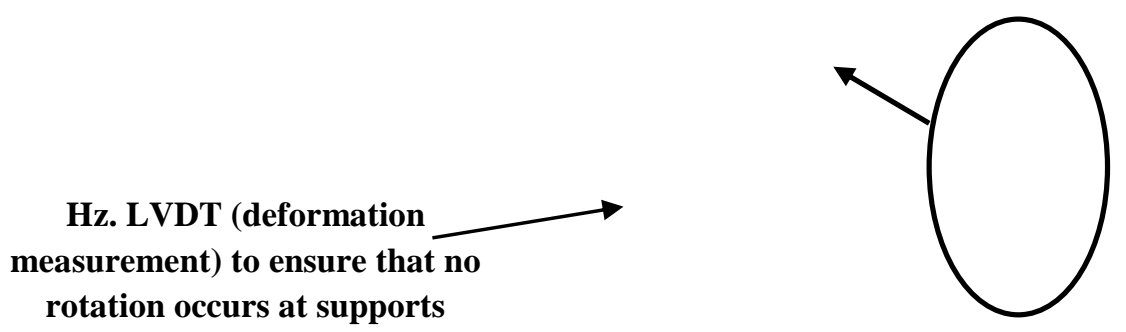

Fig. 8: Main girder fixation to loading frame in laboratory with focused view on steel assembly used to fix main girder in loading frame

Test setup was designed to achieve both safety and stability during the whole experiment. As shown in Figure 9, test load is acting on the cross beam and transmitted to main girder through the joint under study, then to loading frame. Frame columns transmit forces to laboratory rigid floor. Cantilever steel beam supporting loading jack is anchored to a short column through group of ties; this column is also fixed to laboratory floor (Ain Shams University, faculty of Engineering - Reinforced concrete Lab).
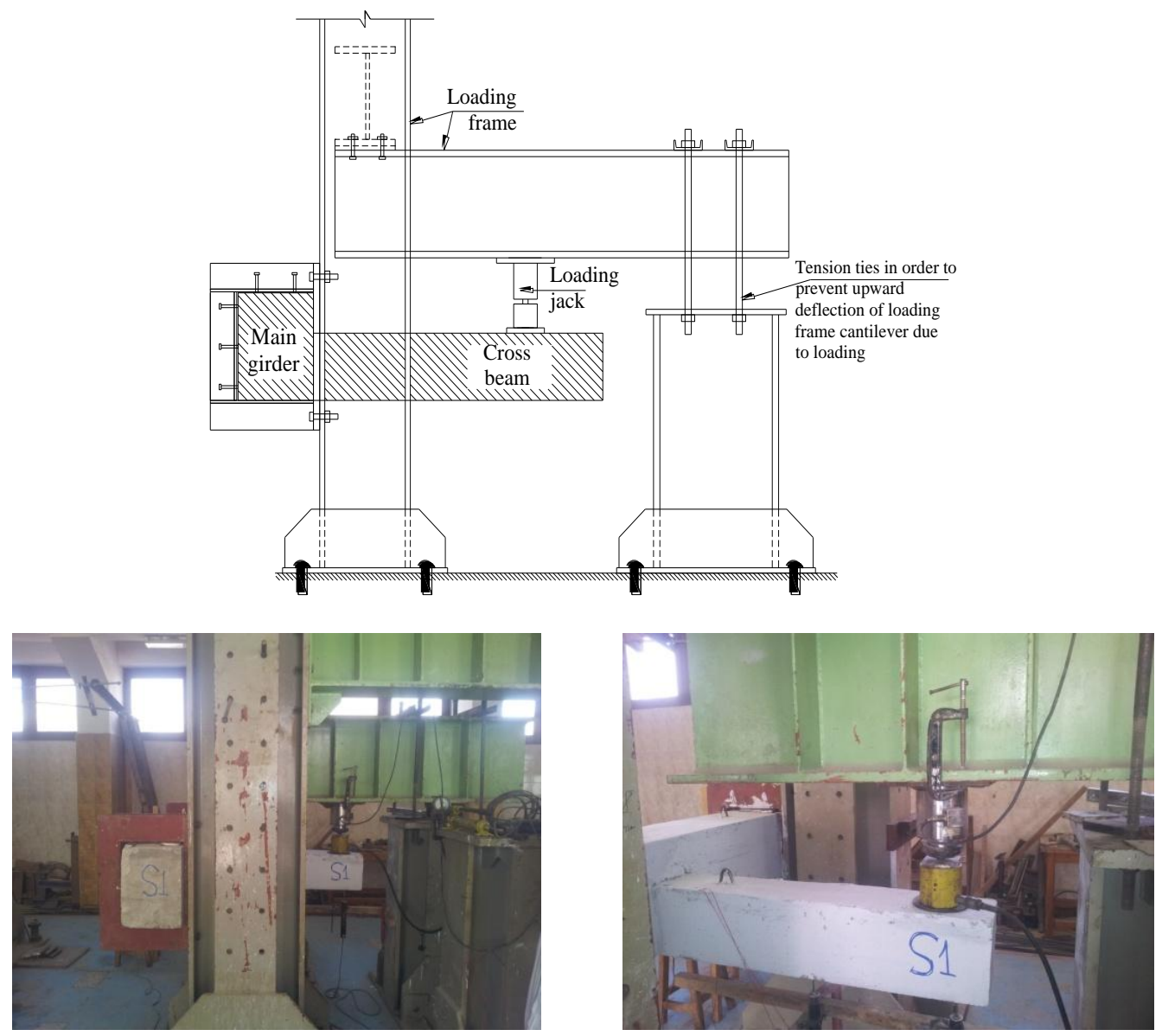

Fig. 9: Test setup photos and scheme 


\section{EXPERIMENTAL RESULTS AND DISCUSSION}

\subsection{Structural Behaviour and cracking pattern of Specimens}

For specimens of group-I that had monolithic joints between beams; specimen (S1) indicated identical behavior of cantilever subjected to bending; flexure cracks were observed at load $15 \mathrm{kN}$ in tension side of cross beam, crack widths and numbers have increased along beam with increasing load till failure at $61 \mathrm{kN}$ with ductile flexural failure mode.

For specimen (S2), flexural cracks started to appear at load $20 \mathrm{kN}$ then increased with loading. Shear diagonal cracks towards loading point were initiated at $40 \mathrm{kN}$ load and increased till the cross beam failed by shear at $75 \mathrm{kN}$.

At early stages of loading of specimen (S3), no flexural cracks were observed, as moment arm is relatively small to develop bending moment that can initiate observable tension cracks. Inclined shear cracks started to appear at load $45 \mathrm{kN}$ from joint with main girder towards loading point. As the load increases the number and width of shear cracks increase till cross beam failed at $103 \mathrm{kN}$ by shear mode.

For group-II specimens, specimen (S4) flexure cracks were observed at load $15 \mathrm{kN}$ in tension side of cross beam. As load increased, crack widths and numbers increased within stitching joint zone. Failure occurred at $44 \mathrm{kN}$; failure mode was flexural with relatively large number of cracks concentrated in stitching joint zone.

In specimen (S5), flexural cracks started to appear at load $20 \mathrm{kN}$ then increased with loading. Shear diagonal cracks towards loading point were initiated at $45 \mathrm{kN}$ load and increased till the cross beam failed by shear mode at $63 \mathrm{kN}$.

Regarding specimen (S6), as previously noticed in specimen (S3), no flexural cracks were observed at early stages of loading. Inclined shear cracks started to appear at load $45 \mathrm{kN}$ from main girder towards loading point. As the applied load increases the number and width of shear cracks increase till cross beam failed by shear mode at $109 \mathrm{kN}$.

As for LVDT attached to fixation assembly of main girder, no significant reading was observed during all experiments, which means that adopted fixation system is reliable to prevent torsional rotation of main girder.

Figures from 10 to 15 show group-I and II specimens crack pattern at failure. In addition, Table 2 summarizes modes of failure as well as ultimate load at failure for each specimen.

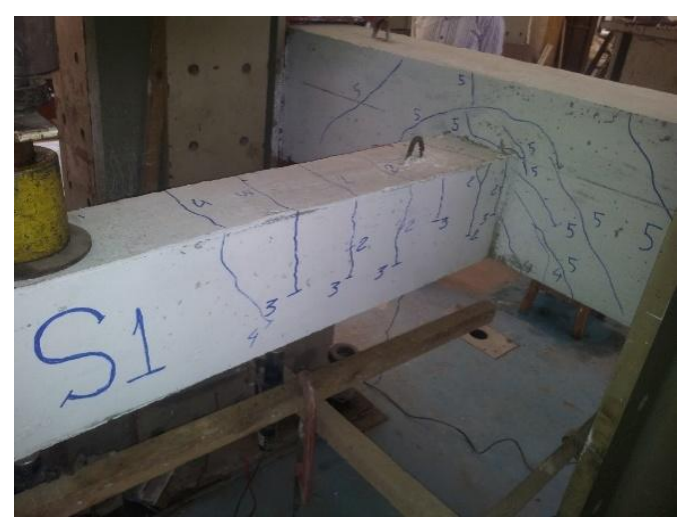

Fig. 10: Specimen-S1 crack pattern at failure

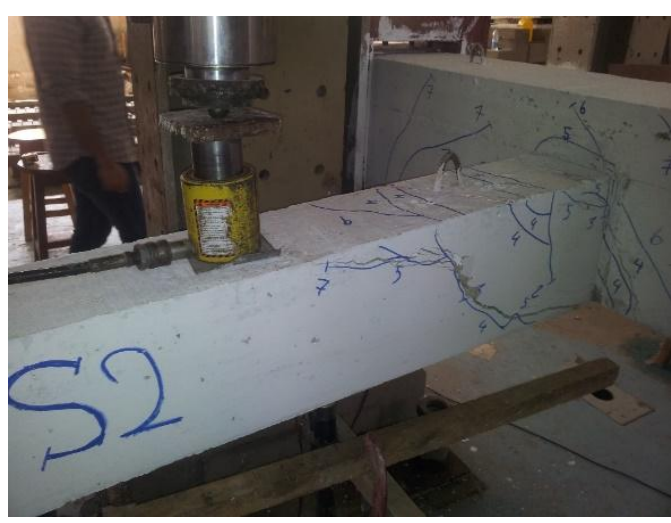

Fig. 11: Specimen-S2 crack pattern at failure 


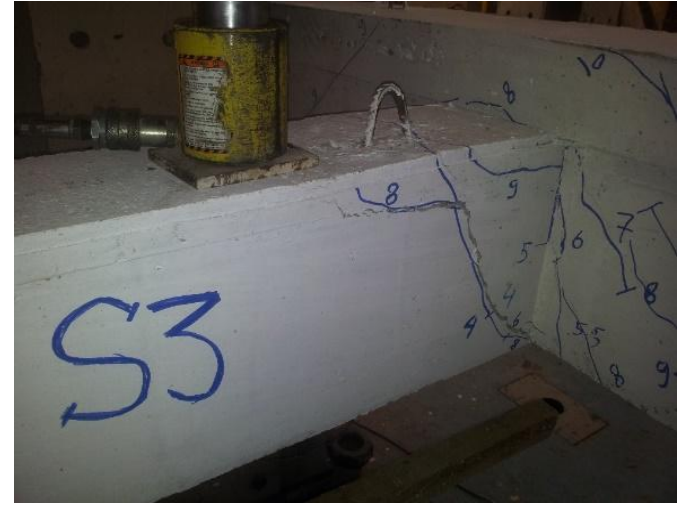

Fig. 12: Specimen-S3 crack pattern at failure

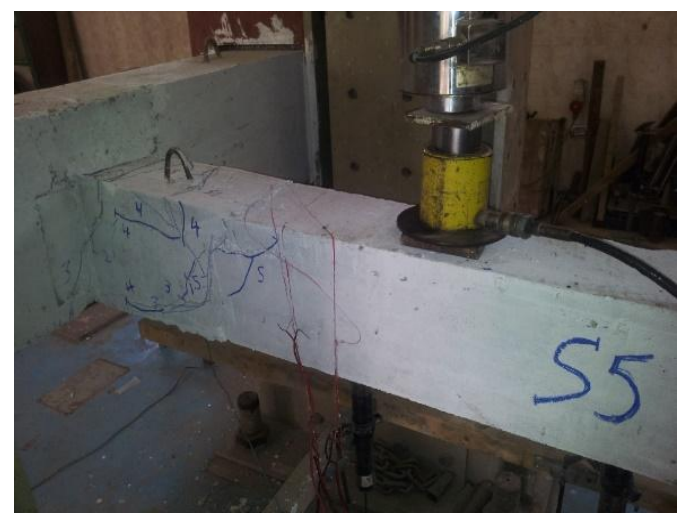

Fig. 14: Specimen-S5 crack pattern at failure

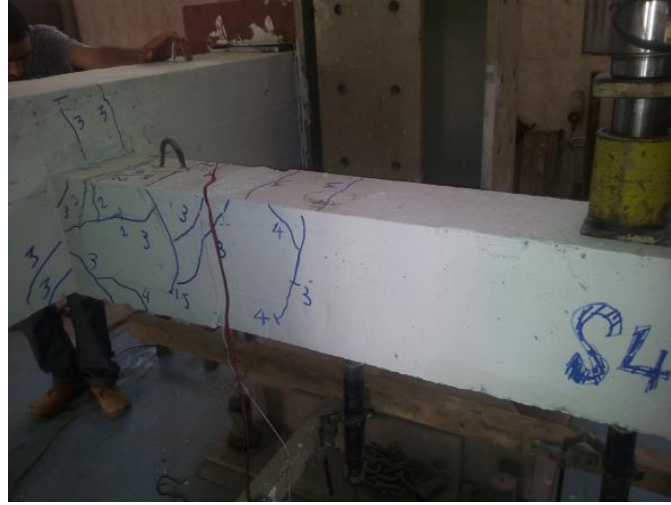

Fig. 13: Specimen-S4 crack pattern at failure

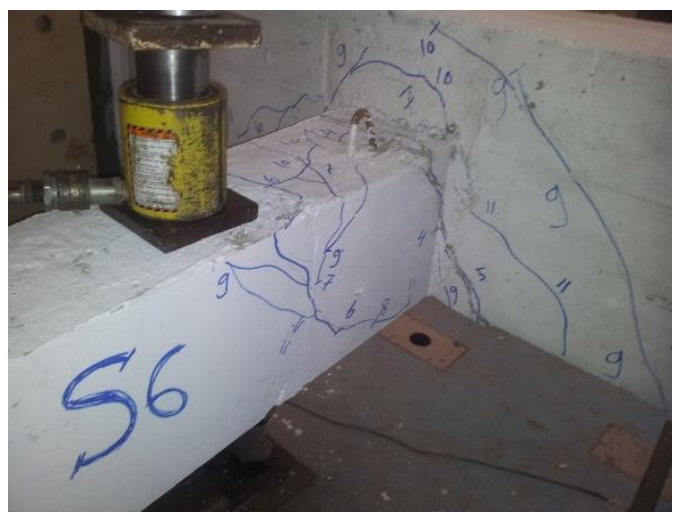

Fig. 15: Specimen-S6 crack pattern at failure

Table 2: Failure loads and modes of tested specimens

\begin{tabular}{|c|c|c|}
\hline $\begin{array}{c}\text { Specimen } \\
\text { number }\end{array}$ & $\begin{array}{c}\text { Failure } \\
\text { Load }(\mathbf{k N})\end{array}$ & $\begin{array}{c}\text { Mode of } \\
\text { failure }\end{array}$ \\
\hline S1 & 61 & Flexural \\
\hline S2 & 75 & Shear \\
\hline S3 & 103 & Shear \\
\hline S4 & 44 & Flexural \\
\hline S5 & 63 & Shear \\
\hline S6 & 109 & Shear \\
\hline
\end{tabular}

\subsection{Load versus deflection and strain relationships:}

The experimental results of load - deflection curves at tip of cross beam cantilever and loadstrain of both concrete and steel were plotted for the seven tested specimens as shown in Figures from 17 to 25 .

For specimens expected to fail in flexural mode (i.e. S1and S4), tension steel strain and concrete compressive strain were recorded as load increasing. While for specimens failed in shear (i.e. S3 and S6), load - shear reinforcement strain relationship was captured. Specimens (S2) and (S5) are intermediate cases, as such strain gauges were placed on both tension and shear reinforcement in addition to concrete compression strain gauge. Deflection readings at cantilever end were measured for all specimens. Figure 16 shows locations of strain gauges used as well as LVDT for deflection measurements. 


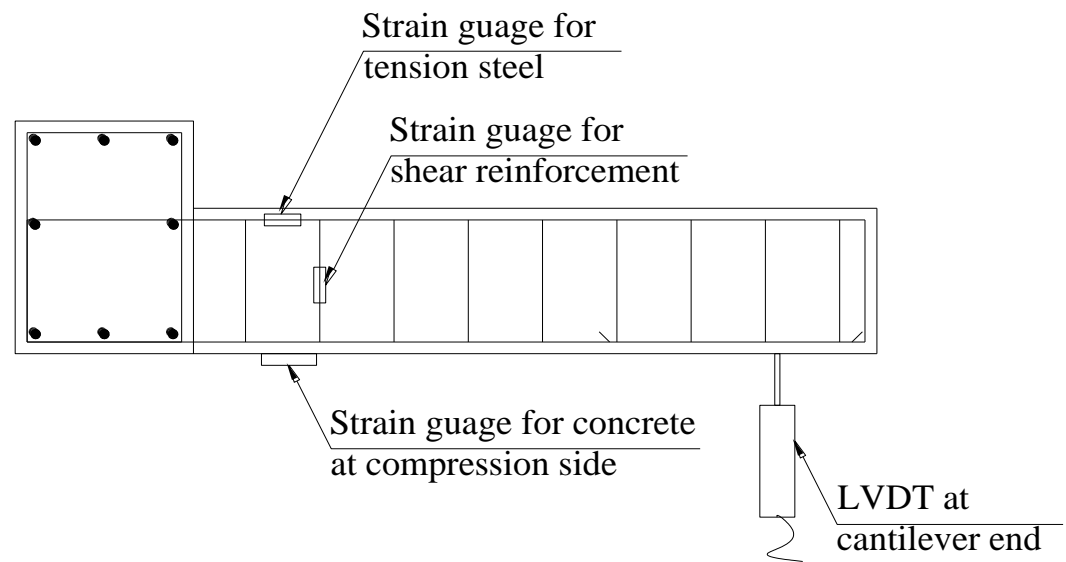

Fig. 16: Locations of strain gauges and LVDT used in measurements

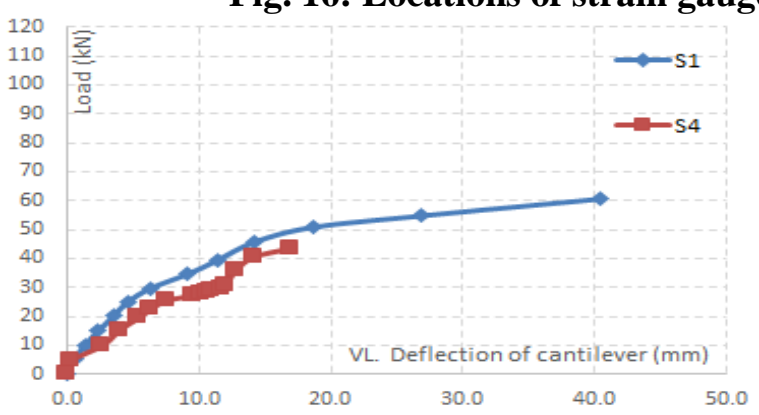

Fig. 17: Experimental plots of load - deflection curves of flexural failure specimens

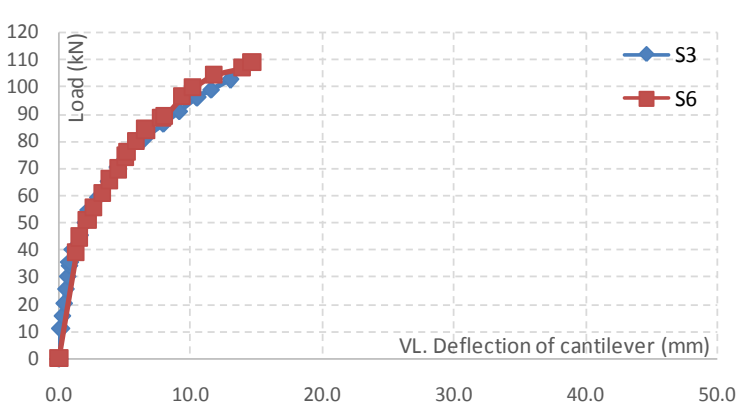

Fig. 19: Experimental plots of load - deflection curves of shear failure specimens

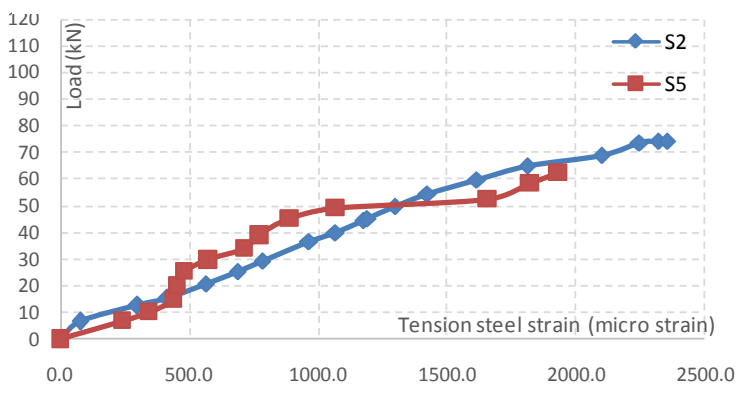

Fig. 21: Experimental plots of load - tension stee strain curves of flexure / shear specimens

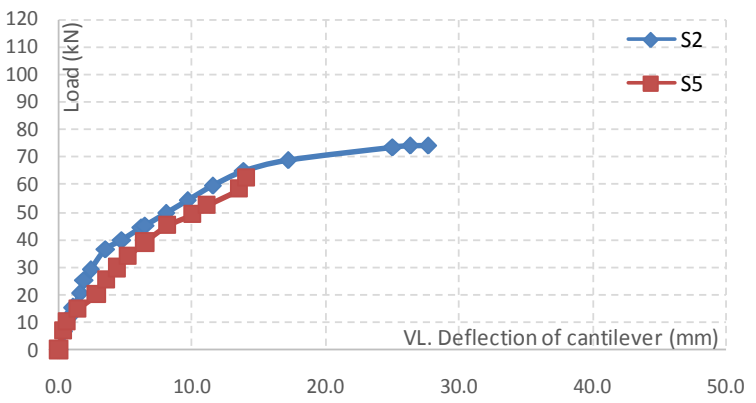

Fig. 18: Experimental plots of load - deflection curves of flexure / shear specimens

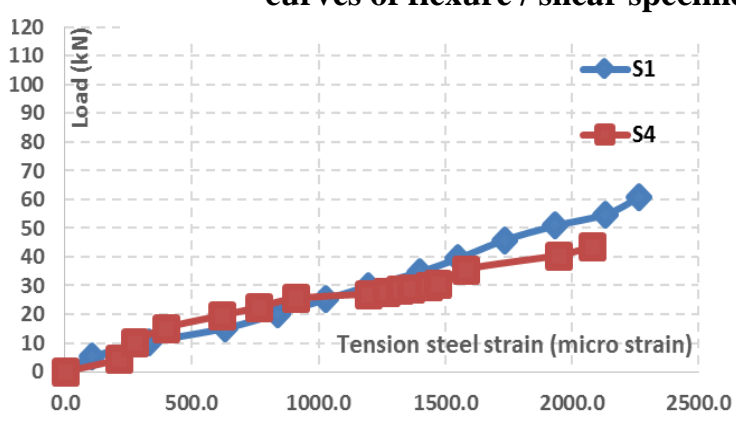

Fig. 20: Experimental plots of load - tension steel strain curves of flexural failure specimens

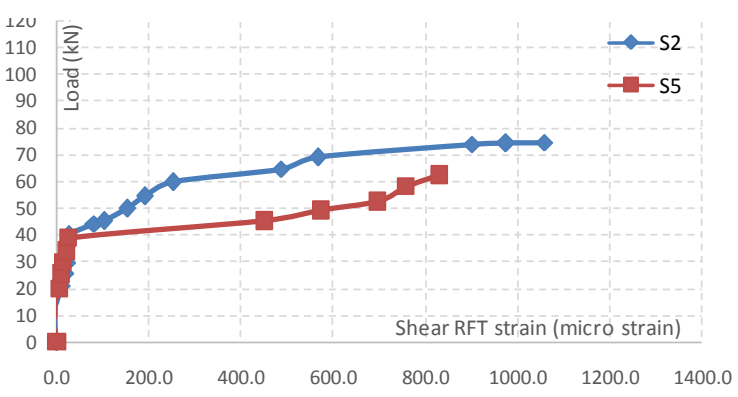

Fig. 22: Experimental plots of load - shear reinforcement strain curves of flexure / shear specimens 


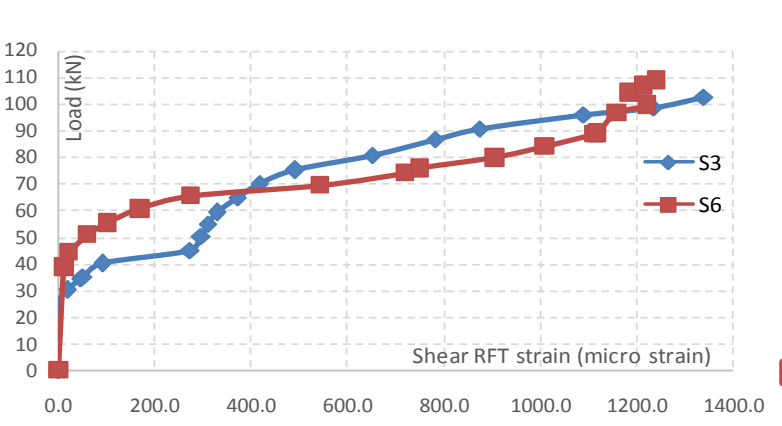

Fig. 23: Experimental plots of load - shear reinforcement strain curves of shear failure specimens

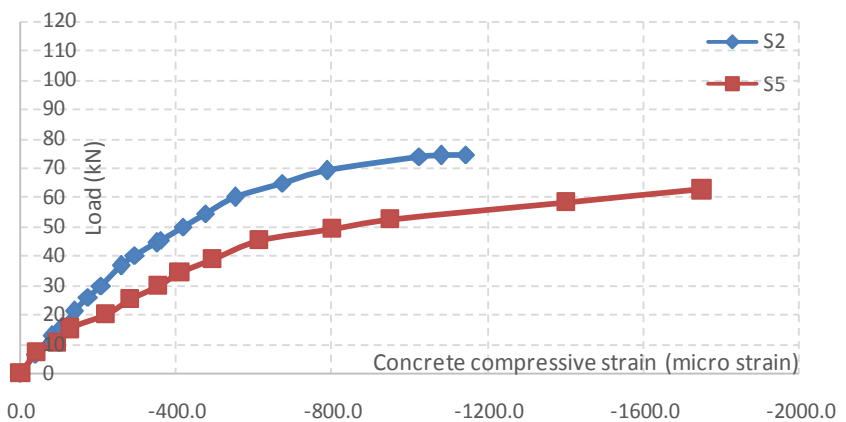

Fig. 25: Experimental plots of load - concrete compressive strain curves of flexural - shear specimens

\subsection{Discussion of experimental results:}

Group-I specimens have shown an identical load-deflection curves in which there is a linear relationship between load and deflection at the first stage of curve as the reinforcement steel and concrete were within their elastic stages and work together. Then relation becomes nonlinear slowly with the increasing load application due to stiffness loss of the cross beam through the loading application. While Group-II, specimens have shown load-deflection curves with some irregularities due to discontinuity of tension steel through the joint between main girder and cross beam.

Flexural capacity of stitching specimen (S4) is relatively low if compared with monolithic specimen (S1) due to steel discontinuity, joint between different casts of concrete and reduction of reinforcement splice to limit joint zone area which have decreased moment capacity of stitching joint by about $25 \%$. It should be mentioned that cross beams in stitching joint specimen (S4) has higher concrete compressive strain at failure due to reinforcement duplication over the stitching joint at critical section of flexure which makes concrete tends to brittle behavior; that is why (S4) had larger number of cracks within stitching joint zone than monolithic specimen (S1).

Shear capacity of both monolithic specimen (S3) and stitching specimen (S6) are almost the same when subjected to pure shear with insignificant flexure, it should be mentioned that shear cracks developed in stitching joint specimen (S6) at failure were not affected by interface between precast and cast-in-situ joint as good preparation of surface enhances shear friction along the interface.

As for specimens that are subjected to both flexure and shear cracking, stitching specimen (S5) and monolithic specimen (S2), they were failed in shear but stitching specimen had slightly lower shear failure load by around $15 \%$ due to lower flexural capacity, which has negative effect on shear behaviour due to excessive cracking of stitching joint as a result of higher concrete compressive strain. 


\section{CONCLUSION}

The results obtained from experimental tests on the different joints between bridge beams allow the following conclusions to be driven:

- In case of joints that are subjected to flexure, stitching joints with limited joint length (as practical) have a reduced moment capacity compared to that of monolithic joints by $15-25 \%$; as the perfect development of reinforcement guaranteed in monolithic joint cannot be obtained by stitching type in which tension reinforcement of joint was spliced at critical section with reduced development length to minimize stitching part.

- Stitching joints have shown perfect behaviour in shear resistance, shear capacity and crack pattern are identical and very similar to monolithic joints. Bearing in mind, that shear friction failure mode shall be considered in design in order to avoid failure at interface between precast beams and stitching concrete.

\section{REFERENCES}

[1] Chapman, Cheryl Elizabeth, "Behavior of Precast Bridge Deck Joints with Small Bend Diameter U-Bars." Master's Thesis, University of Tennessee, 2010.

[2] Hajar, Simon, Lecointre, and Petitjean, "Construction of the First Road Bridges Made of Ultra-high-performance Concrete", ISHPC (2003).

[3] Saad, F. "Serviceability Limit State Improvement of Precast Concrete Bridge Slab Joints Using GFRP-Fabrics", Scientific bulletin Vol.43, Ain Shams University, Egypt, March 2008.

[4] Lungui Li1; Zhongguo John; Mary E. Griffey; and Ralph G. Oesterle "Improved Longitudinal Joint Details in Decked Bulb Tees for Accelerated Bridge Construction: Concept Development.", ASCE journal of Bridge Engineering, Vol. 15, August 2009.

[5] Benjamin A. Graybeal, "Behavior of Field Cast Ultra High Performance Concrete Bridge Deck Connections Under Cyclic and Static Structural Loading." FHWA Publication No. FHWA-HRT-11-023, November 2010. 